\title{
Synthesis and characterization of Ag-chalcogenide nanoparticles for possible applications in photovoltaics
}

\author{
Subhash Chand, Pankaj Sharma* \\ Nanotechnology Laboratory, Department of Physics \& Materials Science, Jaypee University of Information Technology, \\ Waknaghat-173234, India
}

\begin{abstract}
Bottom-up technique has been used to synthesize Ag-chalcogenide nanoparticles. This work reports on the synthesis of $\mathrm{Ag}_{2} \mathrm{Se}$ by varying the molar ratio of capping agent and $\mathrm{pH}$ of the solution. The synthesized nanoparticles have been characterized in terms of structural parameters using X-ray diffraction. By this technique, various parameters such as crystallite size, dislocation density and strain of the nanoparticles were calculated. The crystallite size decreased with the increase in $\mathrm{pH}$ of the solution. The optical characterization was carried out by UV-Vis-NIR spectrophotometer. With the decrease in the crystallite size, a blue shift in the absorption peak of the nanoparticles was observed. These properties are suitable for energy harvesting with the help of photovoltaics.
\end{abstract}

Keywords: nanoparticles; co-precipitation; structural properties; optical properties

\section{Introduction}

In recent years, the semiconducting chalcogenide nanocrystal material has attracted much attention because of its unique properties in terms of size and shape in comparison to the solid counterparts. The binary chalcogenide semiconductors have gained prominent attention due to their size-dependent optical properties along with other physical, chemical and thermal properties resulting from quantum confinement effect. Silver selenide $\left(\mathrm{Ag}_{2} \mathrm{Se}\right)$ is a member of the silver chalcogenide family. $\mathrm{Ag}_{2} \mathrm{Se}$ is a well-known superionic, nonmagnetic narrow-band gap semiconductor and important thermochromic material, which has a phase transition at $406 \mathrm{~K}$, high-temperature cubic phase $\alpha-\mathrm{Ag}_{2} \mathrm{Se}$ and low-temperature orthorhombic phase $\beta-\mathrm{Ag}_{2} \mathrm{Se}$ [1-4]. $\mathrm{Ag}_{2} \mathrm{Se}$ has promising applications in the field of optoelectronics, photodetectors, photo-rechargeable secondary batteries, luminescent devices, magnetic field sensors, switching devices, superionic conductors, electrochemical potential memory devices, photovoltaic cells etc. [5-10].

*E-mail: pks_phy@yahoo.co.in
Different synthesis methods, such as solgel method, hydrothermal method, sononchemical method are available to prepare silver selenide nanoparticles [11-15]. Co-precipitation method consists in mixing initial precursor solutions and then adding a precipitating agent to precipitate the silver selenide nanoparticles. To maintain a small size of the nanoparticles, surfactant materials are used.

In this paper, we report the synthesis, structural, and optical properties of silver selenide nanoparticles. The nanoparticles have been characterized using XRD and UV-Vis spectroscopy.

\section{Experimental}

\subsection{Chemicals and equipment}

All the chemicals used have been procured from Alfa Aesar and used as received. In a typical synthesis approach for sample a, solution I was synthesized by dissolving $0.955 \mathrm{~g}$ of $\mathrm{AgCl}$ in $20 \mathrm{~mL}$ of double distilled water. The solution was stirred until $\mathrm{AgCl}$ dissolved completely. Then, $0.5311 \mathrm{~mL}$ of 2-mercaptoethanol (2-MPA) was added under continuous stirring. Next, $0.5765 \mathrm{~g} \mathrm{Na}_{2} \mathrm{SeO}_{3}$ and 
immediately after that $3.24 \mathrm{~mL}$ of $\mathrm{NH}_{2} \mathrm{NH}_{2} \cdot \mathrm{H}_{2} \mathrm{O}$ (HD) were added into the solution. Temperature of the solution was maintained at $75{ }^{\circ} \mathrm{C}$ with a variation of $\pm 2{ }^{\circ} \mathrm{C}$. The solution was continuously stirred for $2 \mathrm{~h}$. Solution II was prepared by dissolving $\mathrm{NaOH}$ in double distilled water (4 M). It was heated at $85{ }^{\circ} \mathrm{C}$ and stirred. Solution II was slowly, drop after drop, added to solution I until the precipitate started forming. For sample a, $\mathrm{pH}$ of the solution was maintained at 13 . The solution was left to cool for $8 \mathrm{~h}$.

Flow chart for the synthesis of $\mathrm{Ag}_{2} \mathrm{Se}$ nanoparticles sample a

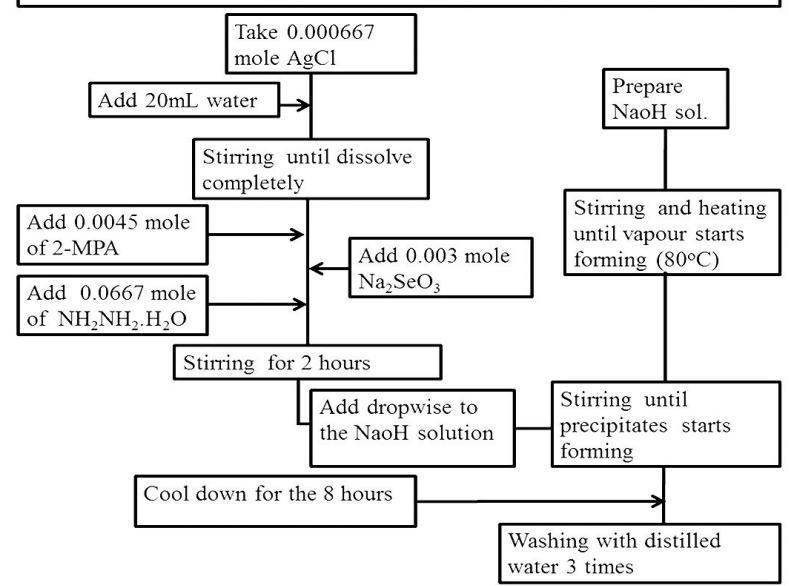

Fig. 1. Schematic of synthesis procedure.

The obtained precipitates were washed several times with distilled water, dried at $60{ }^{\circ} \mathrm{C}$ and crushed to powder using a mortar and a pestle. The flow chart in Fig. 1 presents the schematic of synthesis procedure. Similarly, sample b and sample $\mathrm{c}$ were synthesized using the same procedure with varying ratio of $\mathrm{AgCl}$ to 2-mercaptoethanol, $\mathrm{Na}_{2} \mathrm{SeO}_{3} / \mathrm{HD}$ and changing the $\mathrm{pH}$ of the solution (Table 1). Synthesized nanoparticles were characterized in terms of structural parameters using $\mathrm{X}$-ray diffraction (XRD) (SHIMADZU Analytical: XRD 6000 with $\mathrm{CuK} \alpha(0.154056 \mathrm{~nm})$ operated at $40 \mathrm{kV}$ and $30 \mathrm{~mA}$ ). Optical study was performed using UV-Vis-NIR spectrophotometer (PerkinElmer Lambda 750).

\section{Results and discussion}

\subsection{Reaction mechanism}

Nanoparticles of $\mathrm{Ag}_{2} \mathrm{Se}$ have been synthesized at different $\mathrm{pH}$ values and molar ratios of precursors to the capping agent 2-MPA. Silver chloride first reacts with water to form silver hydroxide. Then, silver hydroxide reacts with 2-MPA to form silver ions capped by 2-MPA molecules. Hydrazine hydrate $\left(\mathrm{N}_{2} \mathrm{H}_{4} \cdot \mathrm{H}_{2} \mathrm{O}\right)$ at equilibrium consists of hydrazinium and hydroxide ion. Thereafter, sodium selenite $\left(\mathrm{Na}_{2} \mathrm{SeO}_{3}\right)$ reacts with hydroxide ion to give hydrogen selenide. Hydrogen selenide reacts with hydrazinium to give selenium ions and finally selenium ions react with silver ions capped with 2-MPA, leading to the formation of 2-MPA capped silver selenide nanoparticles. The reaction process is shown below:

$$
\begin{gathered}
\mathrm{AgCl}+\mathrm{H}_{2} \mathrm{O} \longrightarrow \mathrm{AgOH}+\mathrm{HCl} \\
\mathrm{AgOH}+n\left(\mathrm{HSC}_{2} \mathrm{H}_{4} \mathrm{OH}\right) \longrightarrow\left[\mathrm{Ag}\left(\mathrm{HSC}_{2} \mathrm{H}_{4} \mathrm{OH}\right)_{n}\right]^{+}+ \\
+\mathrm{OH}^{-} \\
\mathrm{N}_{2} \mathrm{H}_{4} \mathrm{H}_{2} \mathrm{O} \rightleftarrows \mathrm{N}_{2} \mathrm{H}_{5}^{+}+\mathrm{OH}^{-} \\
\mathrm{N}_{2} \mathrm{H}_{5}^{+} \rightleftarrows \mathrm{N}_{2}+5 \mathrm{H}^{+}+4 e^{-} \\
\mathrm{Na}_{2} \mathrm{SeO}_{3}+\mathrm{OH}^{-} \rightleftarrows \mathrm{HSe}^{-}+\mathrm{Na}_{2} \mathrm{O}_{4} \\
\mathrm{HSe}^{-}+\mathrm{N}_{2} \mathrm{H}_{5}^{+} \rightleftarrows \mathrm{Se}^{2-}+\mathrm{N}_{2} \mathrm{H}_{2}+4 \mathrm{H}^{+} \\
2\left[\mathrm{Ag}^{\longrightarrow} \mathrm{HSC}_{2} \mathrm{H}_{4} \mathrm{OH}_{n}\right]^{+}+\mathrm{Se}^{2-} \longrightarrow \\
\left.\longrightarrow \mathrm{Ag}_{2} \mathrm{Se}_{(\mathrm{HSC}} \mathrm{H}_{4} \mathrm{OH}\right)_{2 n}
\end{gathered}
$$

\subsection{Structural properties}

Fig. 2 shows the X-ray diffractograms of $\mathrm{Ag}_{2} \mathrm{Se}$ nanoparticles for sample a, sample b and sample c in the $2 \theta$ range from $20^{\circ}$ to $60^{\circ}$. The powder diffraction pattern has been indexed by the assignment of Miller indices ( $\mathrm{h} \mathrm{k} \mathrm{l)}$ to each peak. The results (Miller indices) revealed the orthorhombic structure of $\mathrm{Ag}_{2} \mathrm{Se}$ nanoparticles (JCPDS Card 
Table 1. Synthesis parameters of $\mathrm{Ag}_{2}$ Se nanoparticles.

\begin{tabular}{|c|c|c|c|c|c|c|c|}
\hline \multirow{2}{*}{$\begin{array}{c}\text { Sample } \\
\text { No. }\end{array}$} & \multicolumn{4}{|c|}{ Precursors } & \multirow{2}{*}{$\begin{array}{r}\text { Molar ratio } \\
\mathrm{AgCl} / 2-\mathrm{MPA}\end{array}$} & \multirow{2}{*}{$\begin{array}{r}\mathrm{pH} \text { of } \\
\text { solution }\end{array}$} & \multirow{2}{*}{$\begin{array}{r}\text { Molar ratio } \\
\mathrm{Na}_{2} \mathrm{SeO}_{3} / \mathrm{HD}\end{array}$} \\
\hline & $\begin{array}{c}\mathrm{AgCl} \\
{[\mathrm{g}]}\end{array}$ & $\begin{array}{c}\mathrm{Na}_{2} \mathrm{SeO}_{3} \\
{[\mathrm{~g}]}\end{array}$ & $\begin{array}{c}\text { 2-MPA } \\
{[\mathrm{mL}]}\end{array}$ & $\begin{array}{l}\mathrm{HD} \\
{[\mathrm{mL}]}\end{array}$ & & & \\
\hline $\mathrm{a}$ & 0.955 & 0.5765 & 0.531 & 3.24 & 1 & 13 & 0.05 \\
\hline b & 0.955 & 0.5765 & 0.531 & 3.24 & 1 & 11 & 0.05 \\
\hline c & 0.955 & 0.5765 & 0.312 & 6.47 & 1.5 & 11 & 0.025 \\
\hline
\end{tabular}

Table 2. Various parameters calculated from the XRD patterns.

\begin{tabular}{|c|c|c|c|c|c|c|c|c|c|}
\hline Sample & $\begin{array}{l}2 \theta \\
{\left[{ }^{\circ}\right]}\end{array}$ & \multicolumn{2}{|c|}{$\begin{array}{c}\text { D [nm] } \\
{[\mathrm{nm}]} \\
\text { Obs. Stan. }\end{array}$} & $\begin{array}{c}\text { FWHM } \\
{\left[{ }^{\circ}\right]}\end{array}$ & h k l & \multicolumn{2}{|c|}{$\begin{array}{c}\mathrm{D}[\mathrm{nm}] \\
\text { (Scherer) }\end{array}$} & $\begin{array}{c}\text { Lattice constant } \\
{[\mathrm{nm}]}\end{array}$ & $\begin{array}{r}\delta\left[\mathrm{nm}^{2}\right] \\
{\left[\times 10^{-5}\right]} \\
\text { Avg. }\end{array}$ \\
\hline \multirow{5}{*}{$\mathrm{a}$} & 30.92 & 0.288 & .289 & 0.26 & 102 & 31.68 & \multirow{5}{*}{33.5} & $\mathrm{a}=0.4284$ & 99.58 \\
\hline & 32.69 & 0.273 & .273 & 0.25 & 120 & 33.10 & & $\mathrm{~b}=0.7032$ & 91.26 \\
\hline & 33.48 & 0.267 & .267 & 0.25 & 112 & 33.17 & & $c=0.7605$ & 90.8989 .42 \\
\hline & 34.75 & 0.257 & .258 & 0.24 & 121 & 34.66 & & & 83.19 \\
\hline & 36.98 & 0.242 & .242 & 0.24 & 013 & 34.88 & & & 82.15 \\
\hline \multirow{5}{*}{ b } & 30.92 & 0.288 & .289 & 0.25 & 102 & 32.95 & \multirow{5}{*}{34.3} & $\mathrm{a}=0.4315$ & 92.07 \\
\hline & 32.69 & 0.273 & .273 & 0.24 & 120 & 34.48 & & $\mathrm{~b}=0.7080$ & 84.11 \\
\hline & 33.45 & 0.267 & .267 & 0.25 & 112 & 33.16 & & $\mathrm{c}=0.7778$ & 90.9085 .15 \\
\hline & 34.7 & 0.258 & .258 & 0.24 & 121 & 34.66 & & & 83.22 \\
\hline & 36.97 & 0.242 & .242 & 0.23 & 013 & 36.40 & & & 75.45 \\
\hline \multirow{5}{*}{ c } & 31.03 & 0.287 & .289 & 0.23 & 102 & 35.83 & \multirow{5}{*}{37.4} & $\mathrm{a}=0.4299$ & 77.89 \\
\hline & 32.82 & 0.272 & .273 & 0.22 & 120 & 37.63 & & $\mathrm{~b}=0.7055$ & 70.62 \\
\hline & 33.58 & 0.266 & .267 & 0.22 & 112 & 37.70 & & $\mathrm{c}=0.7748$ & 70.3571 .62 \\
\hline & 34.81 & 0.257 & .258 & 0.23 & 121 & 36.18 & & & 76.38 \\
\hline & 37.08 & 0.242 & .242 & 0.21 & 013 & 39.88 & & & 62.86 \\
\hline
\end{tabular}

No. 24-1041). Table 2 lists the values of full width at half maximum, d-spacing, Miller indices and lattice parameters of $\mathrm{Ag}_{2}$ Se nanoparticles. All diffraction peaks of the samples correspond to the characteristic orthorhombic structure of $\mathrm{Ag}_{2} \mathrm{Se}$ [16]. No traces of impurities have been observed in diffraction patterns which confirms their absence in the synthesized nanoparticles.

Particle size for each peak and average particle size of $\mathrm{Ag}_{2} \mathrm{Se}$ nanoparticles have been calculated using Scherer equation [17]:

$$
D=\frac{k \lambda}{\beta \cos \theta}
$$

where the value of $\mathrm{k}$ is equal to $0.9, \beta$ is the full width at half maximum of the XRD peak and $\mathrm{D}$ is the crystallite size of the nanoparticles. The average nanoparticle size increases from the sample a (33.4 nm), sample b (34.3) nm to sample c (37.4) $\mathrm{nm}$ (Table 2). This increase in the crystallite size between sample a and sample $b$ is due to the decrease in the $\mathrm{pH}$ of the solution. With the decrease in the $\mathrm{pH}$, the number of hydroxyl ions also decreases inside the solution which leads to a decrease in the sulfur ions concentration inside the solution. The increase in the crystallite size between sample b and sample $\mathrm{c}$ is due to the increase in the molar ratio of capping agent. Capping agent restricts the free access of sulfur ions into the silver complex to form $\mathrm{Ag}_{2} \mathrm{Se}$ nanoparticles. 


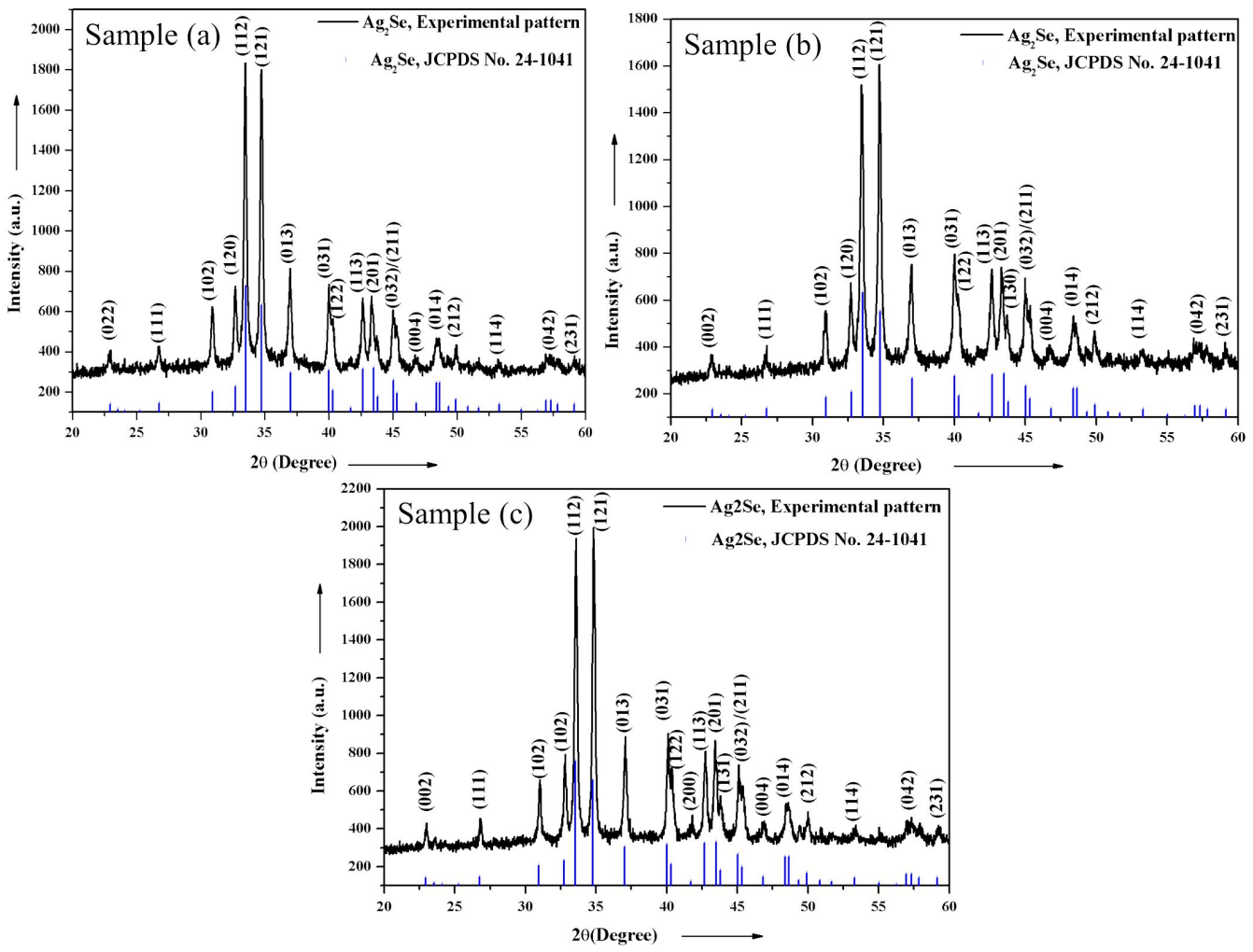

Fig. 2. XRD patterns of $\mathrm{Ag}_{2} \mathrm{Se}$ nanoparticles.

The total peak broadening in X-ray diffraction pattern is constituted by the sum of contributions from crystallite size and the strain existing in the material, and is given by:

$$
\beta=\beta_{D}+\beta_{\varepsilon}
$$

where $\beta_{D}$ is the crystallite size induced broadening, $\beta_{\epsilon}$ is the strain-induced broadening and $\beta$ is the full width at the half-maximum intensity of the corrected instrumental broadening. Presuming the particle size contribution and strain contribution to the line broadening are separate to each other and both show a Cauchy-like profile, then the observed line width is given as [18]:

$$
\beta \cos \theta=\frac{k \lambda}{D}+4 \varepsilon \sin \theta
$$

Equation 10 is called as Williamson-Hall (W-H) equation. W-H equation considers that the strain is uniform in all crystallographic directions and recognized as uniform deformation model (UDM) [19]. This model considers the crystal as isotropic in nature, i.e. the material properties are independent of the direction along which they are measured. A linear fit of the plot $\beta \cos \theta$ as a function of $4 \epsilon \sin \theta$ has been made. The crystallite size $\mathrm{D}$ has been estimated from the intercept of $\mathrm{y}$-axis, and the slope of the linear fit leads to the estimation of microstrain (Fig. 3).

The particle size calculated by the W-H plot method is shown in Table 3 embedded in Fig. 3. There is a difference of approximately $10 \mathrm{~nm}$ in particle size calculated by the $\mathrm{W}-\mathrm{H}$ and the Scherer method. This difference arises because in Scherer formula the parameter $\beta$ includes contribution from the strain of the material. Therefore, we are getting negative slope which gives compressive strain inside the material. The strain decreases with the increase in the particle size. The dislocation density $\delta$, defined as the length of dislocation lines per unit volume of crystal, was evaluated from the formula $\delta=1 / \mathrm{D}^{2}[20,21]$.

Average dislocation density decreases from sample a to sample c (Table 2). 

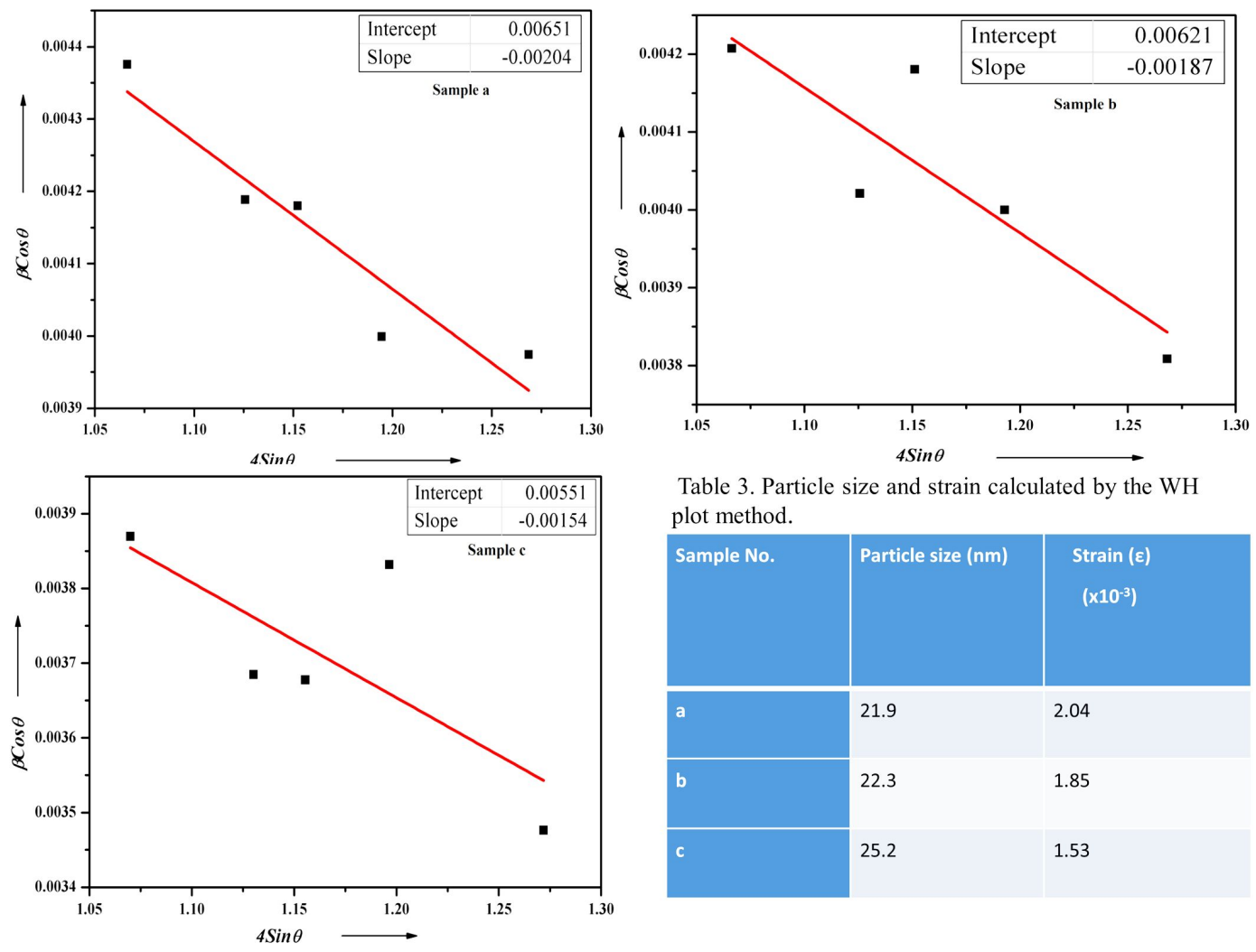

Table 3. Particle size and strain calculated by the WH plot method.

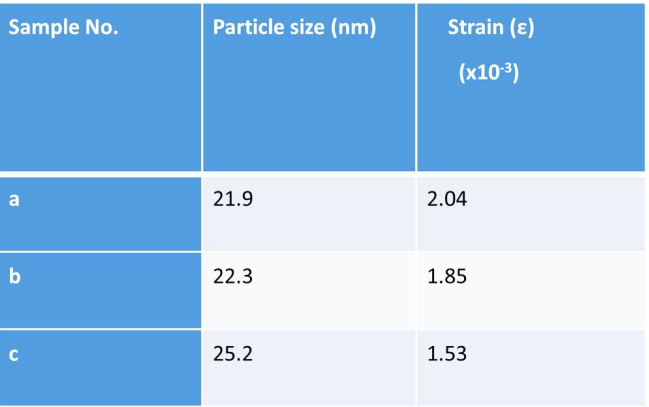

Fig. 3. W-H plots of sample a, sample b and sample c.

\subsection{Optical properties}

The absorption spectra of $\mathrm{Ag}_{2}$ Se nanoparticles in the range of $200 \mathrm{~nm}$ to $700 \mathrm{~nm}$ have been shown in Fig. 4. For sample a, strong absorption at around $270 \mathrm{~nm}$, for sample b at $307 \mathrm{~nm}$ and for sample c at $322 \mathrm{~nm}$ is observed.

The absorption peak of sample a at $270 \mathrm{~nm}$ resembles the absorption peak as reported by Jafari et al. [22]. There is a red shift in the absorption edge with the increase in particle size (XRD results). A blue shift in the absorption edge (band gap) of $\mathrm{Ag}_{2} \mathrm{Se}$ nanoparticles has been observed as compared to the bulk $\mathrm{Ag}_{2} \mathrm{Se}$ and it is due to the quantization effects. The absorption at low wavelength is most probably due to size quantization effects that lead to a series of discrete states in the conduction and valence bands, resulting in the increase of the effective band gap [23-25]. This increase in the band gap of the nanoparticles leads to the more efficient energy harvesting by forming electron hole pairs of large binding energy [26]. The binding

energy of these excitons is larger at room temperature as compared to the bulk material. The synthesized nanoparticles may be suitable for the photovoltaic applications [27].

\section{Conclusions}

We have synthesized $\mathrm{Ag}_{2} \mathrm{Se}$ nanoparticles at varying molar ratio of the constituents and $\mathrm{pH}$ values of applied solutions. Structural parameters have been calculated and show the orthorhombic phase of the nanoparticles. The particle size decreases with an increase in $\mathrm{pH}$. The results obtained from Scherer formula and W-H plots show similar trend. A blue shift in the absorption peak or increase in optical band gap has been observed with the decreasing particles size. This increase in the band gap of the nanoparticle leads to the more effective energy harvesting by forming excitons of large binding energy. It makes the synthesized nanoparticles suitable for the photovoltaic applications. 

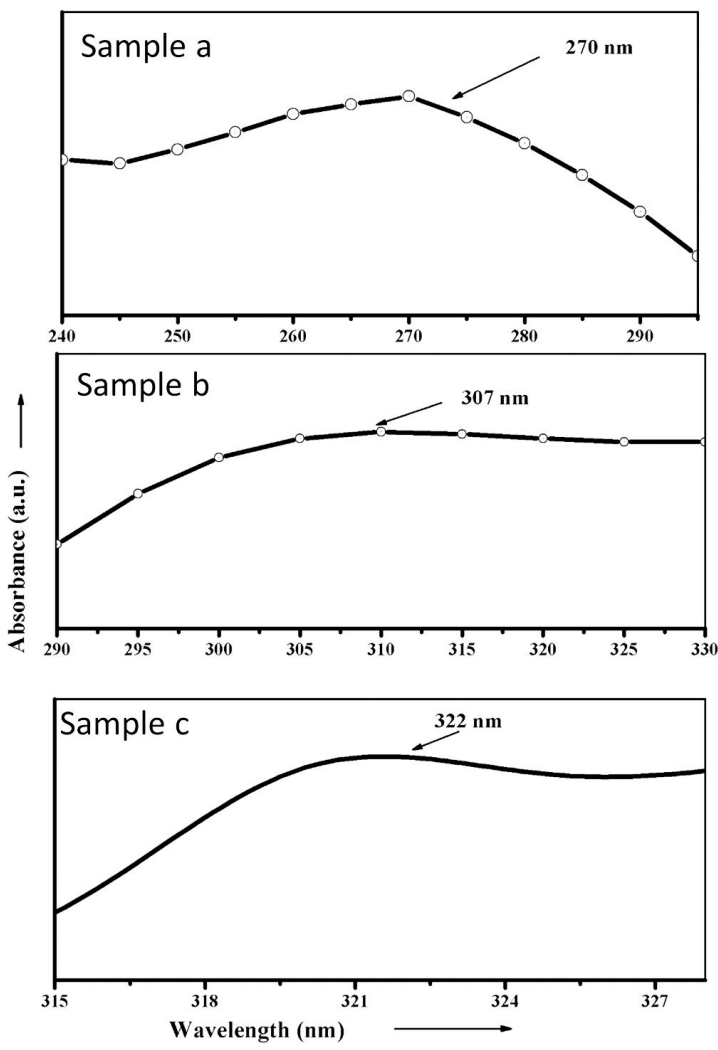

Fig. 4. Absorption spectra of $\mathrm{Ag}_{2} \mathrm{Se}$ nanoparticles.

\section{Acknowledgements}

This work has been financially supported by the Science and Engineering Research Board (SERB), Department of Science and Technology (DST) of India with Project File No. EMR/2014/001108, dated on September 11, 2015. One of the authors (Subhash) is thankful to the SERB-DST, New Delhi, for providing financial support as JRF.

\section{References}

[1] Kumar M.C.S., Pradeep B., Semicond. Sci. Tech., 17 (2002), 261.

[2] Zhu C., Jiang P., Zhang Z., Zhu D., Tian Z., PANG D., ACS Appl. Mater. Inter., 5 (2013), 1186.

[3] Day T., Drymiotis F., Zhang T., Rhodes D., Shi X., Chen L., Snyder G.J., J. Mater. Chem. C, 1 (2013), 7568.

[4] Yang F., LiU F., Yu X., Adv. Mater. Res., 535 (2012), 349.
[5] Pei G.C., Jia D., Jin R ., Xu H., Chen D., New J. Chem., 37 (2013), 323.

[6] Jun J.H., Chо K., Yun J., Kim S., J. Mater. Sci., 46 (2011), 6767.

[7] Gao M.R., Xu Y.F., Jiang J., Yu S.H., Chem. Soc. Rev., 42 (2013), 2986.

[8] Schoen D.T., Xie C., Cui Y., J. Am. Chem. Soc., 129 (2007), 4116.

[9] Sharma P., Sharma N., Sharda S., Katyal S.C., Sharma V., Prog. Solid State Ch., 44 (2016), 131.

[10] Wang W., Geng Y., Qian Y. Ji M., XiE Y., Mater. Res. Bull., 34 (1999), 877.

[11] LiU H., Zhang B., Shi H., TAng Y., Jiao K., FU X., J. Mater. Chem., 18 (2008), 2573.

[12] SAhu A., QI L., KANG M.S., DEng D., NorRis D.J., J. Am. Chem. Soc., 133 (2011), 6509.

[13] Xiao J., Xie Y., Tang R., Luo W., J. Mater. Chem., 12 (2002), 1148.

[14] Jafari M., SAlavati-Niasari M., SAberyan K., Sabarou H., Synth. React. Inorg. M., 45 (2015), 58.

[15] Hu J., Lu Q., TANG K., Qian Y., Zhou G., Cheng H., Deng B., Jiang R., Chem. Commun., 2000 (2000), 715.

[16] Kristl M., Gyergyek S., Kristl J., Mater. Express, 5 (2015), 359.

[17] Bindu P., Thomas S., J. Theor. Appl. Phys., 8 (2014), 123.

[18] Mote V., Purushotham Y., Dole B., J. Theor. Appl. Phys., 6 (2012), 6.

[19] Aly K. A., Khalil N. M., Algamal Y., Saleem Q.M.A., J. Alloy. Compd., 676 (2016), 606.

[20] Aly K. A., Khalil N. M., Algamal Y., Saleem Q.M.A., Mater. Chem. Phys., 193 (2017), 182.

[21] Bilgin V., Kose S., Atay F., Akyuz I., Mater. Chem. Phys., 94 (2005), 103.

[22] Jafari M., Salavati-Niasari M., Saberyan K., SABAROU H., Synth. React. Inorg. M., 45 (2015), 58.

[23] Kumar H., Rani R., Int. J. Eng. Innov. Technol., 3 (2013), 344.

[24] ShuKLa S.K., Adv. Mater. Rev, 1 (2014), 2.

[25] Saleem M., Int. J. Phys. Sci., 7 (2012), 2971.

[26] Kamat P.V., J. Phys. Chem. Lett., 4 (2013), 908.

[27] Chand S., Thakur N., Katyal S.C., Barman P.B., Sharma V., Sharma P., Sol. Energ. Mat. Sol. C., 168 (2017), 183.

Received 2017-01-16 Accepted 2018-05-24 